\title{
Awareness of Diabetic Retinopathy amongst Patients and their Attendants, Attending Diabetes Ophthalmology Clinic - A Population Based Study
}

\author{
Authors \\ Dr Abha Gahlot ${ }^{1}$, Dr Manisha Singh ${ }^{2}$, Dr Iqra Mushtaq ${ }^{3}$, Dr Riti Bhattacharya ${ }^{4}$ \\ ${ }^{1}$ Professor, Dept of Ophthalmology \\ ${ }^{2,3}$ Resident, Dept of Ophthalmology, ${ }^{4} \mathrm{MBBS}$
}

\begin{abstract}
Introduction: According to the International Diabetes Federation, the number of adults afflicted by diabetes in the world is estimated to be 366 million in 2011. Prevalence of Diabetic retinopathy $(D R)$ in diabetic patients is estimated to be $12.2 \%$ to $18.03 \%$. Diabetic retinopathy is one of the leading causes of preventable blindness in India. The purpose of this study was to assess the current status of awareness by sampling the people who attended outpatient department for Ophthalmology checkups.

Material and methods: This was a population based prospective study conducted on 200 patients attending the ophthalmology outpatient department. All the patients were asked to fill a questionnaire containing details such as duration of diabetes and whether or not they were aware of the ophthalmological risks associated with diabetes mellitus and so on.

Results: $60.5 \%$ has had Diabetes for over 5 years and among these $40.49 \%$ go for regular eye examinations. $57.14 \%$ have been diagnosed with diabetic retinopathy. Among the subjects who have had diabetes for more than 5 years, $66.12 \%$ show evidence of diabetic retinopathy. Among 79 subjects who are recently diagnosed cases of diabetes mellitus, 11 cases show diabetic retinopathy the incidence rate being $13.92 \%$.

Conclusion: There is below average awareness of diabetic retinopathy in general population, patients especially the diabetics should be made aware of the ocular risks associated with diabetes and encouraged to undergo regular screening by their family members so as to prevent them from the devastating effects of diabetic retinopathy.
\end{abstract}

\section{INTRODUCTION}

Diabetic retinopathy (DR) is a sight threatening complication of systemic diabetes mellitus that results from damage to the blood vessels of the retina. According to the International Diabetes Federation, the number of adults afflicted by diabetes in the world is estimated to be 366 million in 2011, and is expected to be 552 million in 2030. India has 18 million diabetics. Prevalence of DR in diabetic patients is estimated to be $12.2 \%$ to $18.03 \% .^{1} \mathrm{DR}$ is one of the leading causes of preventable blindness in India. Increased levels of blood glucose are thought to damage the structural and functional integrity of the retinal capillaries. The increase in blood glucose switches the normal glucose metabolic pathway leading to damage of the intramural pericytes of the retinal capillaries, causing weakness and eventual saccular outpouching of capillary walls and loss of retinal capillaries auto-regulation. The relatively selective 
loss of pericytes from the retinal capillaries is a characteristic lesion that occurs early in the course of DR. As the disease progresses, eventual closure of the retinal capillaries occurs leading to hypoxia. More extensive retinal hypoxia triggers compensatory mechanisms within the eye to provide enough oxygen to tissues (e.g. venous calibre abnormalities). Further increases in retinal ischemia trigger the production of vasoproliferative factors that stimulate new vessel formation. Neovascularisation is most commonly observed at the borders of perfused and non perfused retina. They are fragile and highly permeable. If the swelling and exudation involve the macula, a macular oedema and diminution in central vision occurs. ${ }^{2}$ Annual retinal examination and early detection of DR can considerably reduce the risk of visual loss in diabetic individuals. ${ }^{3}$

However due to lack of resources or inadequate knowledge, diabetic patients in India fail to get their eyes examined periodically by registered ophthalmologists. Thus the purpose of this study was to assess the current status of awareness by sampling the people who attended the ophthalmology outpatient department and the weekly diabetic clinic of Dr. D.Y Patil Hospital and Research Centre, Pimpri, Pune.

\section{MATERIALS \& METHOD}

The study was conducted on 200 patients attending the ophthalmology outpatient department and diabetic clinic in Dr. D Y Patil Medical College and Hospital, Pimpri, Pune, India. It was a population based prospective study. The selection criteria for inclusion in the study group are that the patient needs to be a known diabetic in the age group of 30 years and above. The patient should be mentally sound and able to answer questions and in no other way incapacitated.

All the patients were asked to fill a questionnaire. The patients who could not comprehend were explained in vernacular. The questionnaire included the demographic profile of the patients such as their age, sex and occupation, along with other details such as duration of diabetes and whether or not they were aware of the ophthalmological risks associated with diabetes mellitus. The patients were asked other details regarding diabetes such as the duration of the disease, whether they go for periodic eye examinations to an ophthalmologist, and if yes then how frequently, whether they have any risk factors associated with diabetes or not. The visual acuity, retinopathy status and presence of other ocular diseases like glaucoma and age related macular degeneration was assessed. Slit lamp examination of the anterior segment examination was done. Fundoscopy was performed after dilating the pupils.

\section{RESULTS}

Among the 200 subjects interviewed, the following results were obtained. There were 98 females (49\%) and 102 males (51\%).

The age distribution of the population was as follows: [TABLE 1]

The mean age was calculated to be 54.81 years.

The occupation wise distribution of the subjects was as follows. [TABLE 2]

Among the subjects interviewed, 76 subjects (38\%) were aware of diabetic retinopathy and 124 were unaware (62\%). 144 subjects (72\%) were suffering from type II Diabetes mellitus and 56 subjects (28\%) were suffering from type-I Diabetes mellitus.

The duration of diabetes in the subjects is shown as under. [TABLE 3]

Frequency of eye check-ups in subjects is tabulated as under. [TABLE 4]

In the study subjects, 76 (38\%) were advised regular eye examinations by their ophthalmologists and 124 (62\%) were not. Among the subjects $126(63 \%)$ complained of affected vision and $74(37 \%)$ had normal vision. The following risk factors associated with diabetes were observed in the patients:

Hypertension 98, Obesity 27, Family history 36, Heart disease 3. Fundoscopic examination among the subjects revealed diabetic retinopathy (DR) in 
$91(45.5 \%)$ subjects and 109 (54.5\%) patients were found to show no evidence of diabetic retinopathy. On further analysis of the results, it was found that among 91 of the patients suffering from diabetic retinopathy, 21(23.08\%) were aware of the condition and $70(76.92 \%)$ were not. A contingency table has thus been drawn up illustrating the relation of awareness of diabetic retinopathy with its prevalence [TABLE 5]

Thus applying appropriate formulae, the relative risk of diabetic retinopathy is calculated as under Relative risk $=$ (Incidence among unaware) / (incidence among unaware $)=(\mathrm{c} /(\mathrm{c}+\mathrm{d})) /(\mathrm{a} /(\mathrm{a}+\mathrm{b}))$ $=2.04$

Similarly the odds ratio in this case is calculated as:

Odds ratio $=\mathrm{bc} / \mathrm{ad}=\mathbf{3 . 3 9}$

When related to regular eye checkups, among the 91 who were diagnosed with Diabetic retinopathy, $33(36.26 \%)$ went for regular eye checkups, and $58(63.73 \%)$ did not. Among the 109 that were found to be normal, $52(47.71 \%)$ went for regular eye checkups and 57 (52.29\%) did not. In a similar fashion, comparisons have been made and appropriate calculations have been done.

- Out of 200, 121 subjects (60.5\%) has had Diabetes for over 5 years and among these
49 (40.49\%) go for regular eye examinations.

- Among the 121, 28 (57.14\%) have been diagnosed with diabetic retinopathy and 21 $(42.86 \%)$ are normal

- Among the 72 patients who do not attend regular checkups,52 (72.22\%) were diagnosed with Diabetic retinopathy and $20(27.78 \%)$ were normal

- Thus among the subjects who have had diabetes for more than 5 years, 80 show evidence of diabetic retinopathy. The incidence rate is $66.12 \%$

- Similarly in the 79 subjects who are recently diagnosed cases of diabetes mellitus, $36(45.57 \%)$ have undergone eye examination and $43(54.43 \%)$ have not.

- Among the 36 who have undergone eye examination, 2 of the subjects $(5.55 \%)$ have been found to have Diabetic retinopathy.

- Among the 43, who have not undergone examination, 9 (20.93\%) showed signs of diabetic retinopathy

- Thus among the newly diagnosed cases there are 11 cases of diabetic retinopathy the incidence rate is $13.92 \%$

\section{TABLE 1}

\begin{tabular}{|l|l|l|l|l|}
\hline Age group & $<39$ years & $40-49$ years & $50-59$ year & $>60$ years \\
\hline No of patients & $16(8 \%)$ & $40(20 \%)$ & $64(32 \%)$ & $76(38 \%)$ \\
\hline
\end{tabular}

\section{TABLE 2}

\begin{tabular}{|l|l|l|l|l|l|l|l|l|}
\hline Occupation & Professional & $\begin{array}{l}\text { Skilled } \\
\text { labour }\end{array}$ & $\begin{array}{l}\text { Semi- } \\
\text { skilled } \\
\text { labour }\end{array}$ & Farmer & Student & Housewife & Retired & Unemployed \\
\hline No of patients & $22(11 \%)$ & $\begin{array}{l}20 \\
(10 \%)\end{array}$ & $\begin{array}{l}28 \\
(14 \%)\end{array}$ & $6(3 \%)$ & $4(2 \%)$ & $86(43 \%)$ & $\begin{array}{l}32 \\
(16 \%)\end{array}$ & $2(1 \%)$ \\
\hline
\end{tabular}


TABLE 3

\begin{tabular}{|l|l|l|l|l|}
\hline $\begin{array}{l}\text { Duration of } \\
\text { diabetes in years }\end{array}$ & Below 10 & $10-19$ & $20-29$ & Above 30 \\
\hline No of patients & $138(69 \%)$ & $36(18 \%)$ & $24(12 \%)$ & $2(1 \%)$ \\
\hline
\end{tabular}

\section{TABLE 4}

\begin{tabular}{|c|c|c|c|c|c|}
\hline $\begin{array}{l}\text { Frequency of eye } \\
\text { check-ups }\end{array}$ & Once a year & Twice a year & $\begin{array}{l}\text { Once in two } \\
\text { months }\end{array}$ & $\begin{array}{l}\text { Once in a } \\
\text { month }\end{array}$ & Never \\
\hline No of patients & $66(33 \%)$ & $36(18 \%)$ & $4(2 \%)$ & $4(2 \%)$ & $90(45 \%)$ \\
\hline
\end{tabular}

\section{TABLE 5}

\begin{tabular}{|l|l|l|l|}
\hline & DR present & DR absent & \\
\hline Aware & $21(\mathrm{a})$ & $55(\mathrm{~b})$ & $76(\mathrm{a}+\mathrm{b})$ \\
\hline Unaware & $70(\mathrm{c})$ & $54(\mathrm{~d})$ & $124(\mathrm{c}+\mathrm{d})$ \\
\hline & $91(\mathrm{a}+\mathrm{c})$ & $110(\mathrm{~b}+\mathrm{d})$ & \\
\hline
\end{tabular}

\section{DISCUSSION}

On analysing the results, we can draw the following conclusions. The retinopathy awareness rate amongst the patients was average (48\%). This is significantly different from studies conducted in Myanmar ${ }^{4}$ where retinopathy awareness rate amongst diabetic outpatients was $86 \%$ and the study conducted in Nigeria (84.3\%). ${ }^{5}$ This can be attributed to general lack of awareness among the residents of the Pimpri Chinchwad municipal corporation area and lack of proper health educational services among general populous. In this study most of the patients attributed their source of information on diabetic retinopathy to the hospital environment, such as doctors, nurses or other health care professionals. Other sources such as the mass media or the Internet did not seem to play any significant role, as subjects did not cite these sources as their means of awareness. Other sources of information are family members or friends who have had similar complaints.

The odds of unaware patients developing diabetic retinopathy is 3.39 times those of aware patients.
This is due to the fact that people who are aware of the dangers of retinopathy opt for regular ophthalmological examination with a registered ophthalmologist. Regular examination enables early detection of diabetic retinopathy. Another observed feature is that prevalence of diabetic retinopathy is much higher in subjects who have had diabetes for more than 5 years i.e. the old cases $(66.12 \%)$ than in recently diagnosed patients (13.92\%)

Thus prevalence of diabetic retinopathy is much lower in the newly diagnosed cases. The other factor related to diabetic retinopathy is screening. Ideally patients with diabetic retinopathy should undergo routine fundus examinations as follows:

- Every year: till there is no diabetic retinopathy or mild NPDR

- Every 6 months: in moderate NPDR

- Every 3 months: in severe NPDR

- Every 2 months: in PDR with no high risk characteristic. $^{6}$ 


\section{CONCLUSION}

There is below average awareness of diabetic retinopathy amongst the patients with the main source of information about retinopathy being hospital staff and fellow patients. The population, especially the diabetics should be made aware of the ocular risks associated with diabetes and encouraged to undergo regular screening by their family members, hence comes the importance of their awareness.

Blindness being a devastating complication of diabetes, the importance of early diagnosis and treatment of retinopathy through screening needs to be emphasized.

\section{REFERENCES}

1. Namperumalsamy $\mathrm{P}$, Kim R, Vignesh TP, Nithya N, Royes J, Gijo T. Prevalence and risk factors for diabetic retinopathy: a population-based assessment from Theni District, south India. Postgrad Med J. 2009;85(1010):643-8.

2. Diabetic retinopathy. Edited by O Paul van Bijsterved, Martin Dunitz Ltd, London, 2000

3. Rema M, Pradeepa R. Diabetic retinopathy: an Indian perspective. Indian J Med Res. 2007 Mar;125(3):297-310...

4. Addoor KR, Bhandary SV, Khanna R, Rao LG, Lingam KD, Shivaji $S$ et al. Assessment of awareness of diabetic retinopathy among the diabetics attending the peripheral diabetic clinics in melaka, Malaysia. Med J Malaysia. 2011;66(1):4852

5. Cetin EN, Zencir M, Fenkçi S, Akın F, Yildirım C. Assessment of awareness of diabetic retinopathy and utilization of eye care services among Turkish diabetic patients. Prim Care Diabetes 2013 Dec;7(4):297-302.
6. Thapa R, Poudyal G, Maharjan N, Bernstein PS. Demographics and awareness of diabetic retinopathy among diabetic patients attending the vitreoretinal service at a tertiary eye care center in Nepal. Nepal $\mathbf{J}$ Ophthalmol. 2012;4(1):10-6. 